\title{
Quality of Life After Bilateral Risk-Reducing Mastectomy and Simultaneous Reconstruction Using Pre-Pectoral Silicone Implants
}

This article was published in the following Dove Press journal: Patient Preference and Adherence

\author{
Nick Spindler' \\ Franziska Ebel' \\ Susanne Briest ${ }^{2}$ \\ Sandra Wallochny ${ }^{2}$ \\ Stefan Langer' \\ 'Department of Orthopedic Surgery, \\ Traumatology and Plastic Surgery, \\ University Hospital Leipzig, Leipzig, \\ Germany; ' ${ }^{2}$ Department of Gynecology, \\ Women's and Children's Centre, \\ University Hospital Leipzig, Leipzig, \\ Germany
}

Purpose: Bilateral risk-reducing mastectomy (BRRM) can reduce the risk of developing breast cancer by up to $95 \%$ in women with increased exposure. Although survival is increased, mastectomies can adversely affect a patient physically, psychologically, and psychosexually. High health-related quality of life (HRQoL) is often achieved after simultaneous breast reconstruction (BR) following BRRM; however, data on the pre- and postoperative results of HRQoL are lacking. Therefore, we investigated the quality of life, esthetic outcome, and patient well-being after BRRM and simultaneous implant-based BR.

Patients and Methods: Of the 35 patients who underwent skin-sparing or nipple-sparing mastectomy between May 2012 and December 2017 at a university hospital, only 22 completed the evaluation. Baseline data and data on previous operations and operation techniques were retrieved from the patient's charts. BREAST-Q and short form-36 health survey (SF-36) questionnaires were used to evaluate patient satisfaction and HRQoL.

Results: SF-36 analysis showed a significantly higher score for pain $(p=0.043)$ in our population than in the general female population. Comparing the pre- and postoperative BREAST-Q results, a significant decrease in the physical well-being of the chest $(p=0.0179)$ and a slight improvement in breast satisfaction were observed $(\mathrm{p}=0.3266)$. All patients were well-satisfied with the postoperative outcome, reconstruction, and perioperative surgeon care. Conclusion: Bilateral mastectomy with simultaneous BR using pre-pectoral implants is associated with an HRQoL similar to that of the healthy population. Although bilateral mastectomy may have an immense effect on the psychological, physical, and social aspects, immediate BR preserves the outer appearance and improves self-esteem.

Keywords: risk-reducing mastectomy, implant-based reconstruction, $B R C A 1, B R C A 2$, skinsparing mastectomy, nipple-sparring mastectomy

\section{Introduction}

Breast cancer is the most common cause of cancer-related death among North American and Western European women. ${ }^{1}$ A family predisposition exists in more than $25 \%$ of cases. ${ }^{2,3}$ Women carrying a pathogenic mutation in the breast cancer gene 1 or $2(B R C A)$, as well as those with other genetic susceptibilities or underlying hereditary diseases, are at increased risk of developing breast cancer. ${ }^{4,5}$

Reports suggest that bilateral risk-reducing mastectomy (BRRM) reduces the risk of breast cancer by up to $95 \%$ in women with the $B R C A$ gene mutation and up to $90 \%$ in women with strong family predisposition. ${ }^{6-9}$ Skin-sparing mastectomy (SSM) or nipple-sparing mastectomy (NSM) is oncologically safe and associated
Correspondence: Nick Spindler

Department of Orthopedic Surgery, Traumatology and Plastic Surgery, University Hospital Leipzig, Liebigstrasse 20, Leipzig, 04103, Germany

Tel +49-34I-97I7| 40

Fax +49-34I-9717139

Email nick.spindler@medizin.uni-leipzig.de
Patient Preference and Adherence 2021:15 74I-750

741

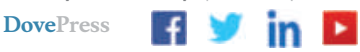

http://doi.org/10.2147/PPA.S303208 
with improved esthetic outcomes. ${ }^{10}$ Studies based on recurrence and survival rates after NSM and SSM have reported equal oncological safety. ${ }^{11-13}$ In contrast, bilateral mastectomies are irreversible, highly intrusive, and may be associated with severe complications. ${ }^{14}$

Anxiety about developing breast cancer has supported a greater demand for mutation testing and BRRM. ${ }^{5}$ Positive media coverage of celebrities undergoing riskreducing mastectomy with immediate breast reconstruction (BR) has further promoted this therapeutic option. Until now, the literature has focused mainly on the effectiveness and safety of BRRM with regard to cancer, morbidity, and mortality rates, as well as consideration of established risk models. ${ }^{1,6,7,15}$ Although survival is improved, mastectomy can adversely impact the patient, not only at a physical level, but also at psychological and psychosexual levels. ${ }^{16}$ BRRM results in permanent change to one's appearance and affects self-esteem and healthrelated quality of life (HRQoL). To assess HRQoL, the 36item Short Form Health Survey (SF-36) can be used as a non-disease-specific and non-organ-specific measuring instrument. Since its introduction, the SF-36 has been continuously developed and is frequently used to monitor the effect of therapy or disease progression. ${ }^{17-20}$ Because of the lack of organ-specific questionnaires to quantify HRQoL after esthetic or reconstructive breast surgery, the BREAST-Q was developed by the Memorial SloanKettering Cancer Center and the University of British Columbia. $^{21-24}$

Although high postoperative HRQoL after simultaneous BR following BRRM has been reported, data comparing pre- and postoperative results of HRQoL tests are lacking. Therefore, in this study, we evaluated HRQoL, esthetic outcomes, and changes in patient well-being using the SF-36 and BREAST-Q questionnaires preoperatively and after BRRM and simultaneous implant-based BR.

\section{Patients and Methods Study Population}

The prospective single-center study protocol was approved by the institutional ethics committee (021/17-ek) and was performed in accordance with the Declaration of Helsinki. Written informed consent for the publication of all data and accompanying images was obtained from all patients.

This analysis reviewed 35 patients who underwent SSM or NSM between May 2012 and December 2017 at the University Hospital of Leipzig.
The inclusion criteria were as follows: female sex, diagnosis of a gene mutation predisposing to breast cancer; SSM or NSM with a simultaneous pre-pectoral implant-based reconstruction; and age $\geq 18$ years. Conversely, the exclusion criteria were as follows: patients with current cancer and/or on cancer therapy, patients who needed translation assistance for verbal consent and age $<18$ years.

Conversely, the exclusion criteria were as follows: patients with current cancer and/or on cancer therapy, patients who needed translation assistance for verbal consent and age $<18$ years.

The operation choice (NSM vs SSM) was made after detailed information regarding the varying degrees of the remaining residual glandular tissue and the associated risk of developing breast cancer as well as possible occurring side effects and general complications were explained to the patient. After considering the risk and benefit of both procedures, the operative strategy was determined by the patient.

The medical records of each patient were reviewed and baseline data including demographic information, results of standard laboratory tests, medical history, list of current medications, allergies, and operative techniques were retrieved from the patient's charts.

Pre- and postoperative mastectomy modules of the BREAST-Q and SF-36 questionnaires were used to evaluate patient satisfaction and $\mathrm{HRQoL}$, respectively. Preoperative questionnaires were completed within the week before the operation by the patients themselves. At the follow-up consultation, the evaluation of the postoperative BREAST-Q and SF-36 were administered, and patients underwent breast and upper body measurements. Follow-up was conducted in a mean of 2.15 years (standard deviation [SD] 1.58) after the surgery. During the follow-up investigation a physician performed the clinical inspection and the patients filled out the postoperative questionnaires. The clinical examination included measurements of the breasts and upper body as well as examination of breast sensitivity.

To test the sensitivity, a matrix was applied on the surface of the breast. The absence or presence of touch sensitivity to the Semmes-Weinstein monofilament at the crossing points was recorded. The filament had a thickness of $2.83 \mathrm{~mm}$ and the crossing points had a distance of $1 \mathrm{~cm}$ to each other. Thus, a sensitivity mapping of the breast was achieved. The results were then assigned to three grades dependent on the lack of sensitivity; grades I, II, and III were defined as a loss of sensitivity of $<30 \%, 30-60 \%$, and $>60 \%$, respectively. 
The absence or presence of touch sensitivity to the Semmes-Weinstein monofilament $(2.83 \mathrm{~mm}$ thick $)$ at the crossing points (1 cm apart) was recorded. The filament had a thickness of $2.83 \mathrm{~mm}$ and the crossing points had a distance of $1 \mathrm{~cm}$ to each other. Thus, creating a sensitivity mapping of the breast was achieved. The results were then assigned to three grades dependent depending on the lack of sensitivity; Grades I, II, and III were defined as a loss of sensitivity of $<30 \%, 30-60 \%$, and $>60 \%$, respectively.

\section{Surgical Technique}

All patients were marked before surgery in a standing position. For reconstruction of the breast, a Wise pattern mastopexy was performed in all patients. Incisions were made around the areola, and the new position of the areola continued down to the inframammary fold following an inverted-T incision line. Before mastectomy, the area between the limbs was deepithelialized. Thereafter, an inferior pedicled flap was raised before the mastectomy was performed. The NAC was preserved and superiorly pedicled. After resection of the gland, we measured and weighed the tissue and selected an appropriate implant, which was placed in the pre-pectoral plane. Thereby, an optimal implant position on the chest wall in accordance with the mastectomy borders could be achieved. The use of artificial material and acellular dermal matrix was avoided. Instead, coverage of the lower implant pole was performed using the raised deepithelialized semilunar flap. In this manner, a pocket for the implant, as well as an inframammary fold, was created. Furthermore, adequate wall thickness at the lower breast pole could be guaranteed. ${ }^{25}$

One suction drain was inserted into the subcutaneous pocket. Drains remained for at least $24 \mathrm{~h}$ and were removed when secretion was less than $30-40 \mathrm{cc} /$ day. We recommended that the patients wear a compression bra for 6 weeks (Figure 1).

\section{Study Instruments \\ SF-36}

To assess patients' postoperative quality of life, the SF-36 questionnaire was used. SF-36 measures HRQoL and was developed in 1990 based on the medical outcomes study. ${ }^{17,26}$ The test instrument includes 36 items divided into eight areas reflecting patient health: physical functioning, role limitation due to physical health, body pain, general health perception, vitality, social role functioning, and role limitation due to emotional health and mental health. ${ }^{17,19,27,28}$ Each scale is scored from 0 to 100 , with 0 representing the worst health status and 100 the best health status.

\section{BREAST-Q}

BREAST-Q is a specific tool for patients undergoing breast surgery to evaluate and investigate HRQoL and patient satisfaction. ${ }^{16,29-31}$ The preoperative version of the BREAST-Q reconstruction module assesses: satisfaction with breasts, satisfaction with overall outcome, psychosocial well-being, sexual well-being, and physical well-being of the chest. In the postoperative evaluation,
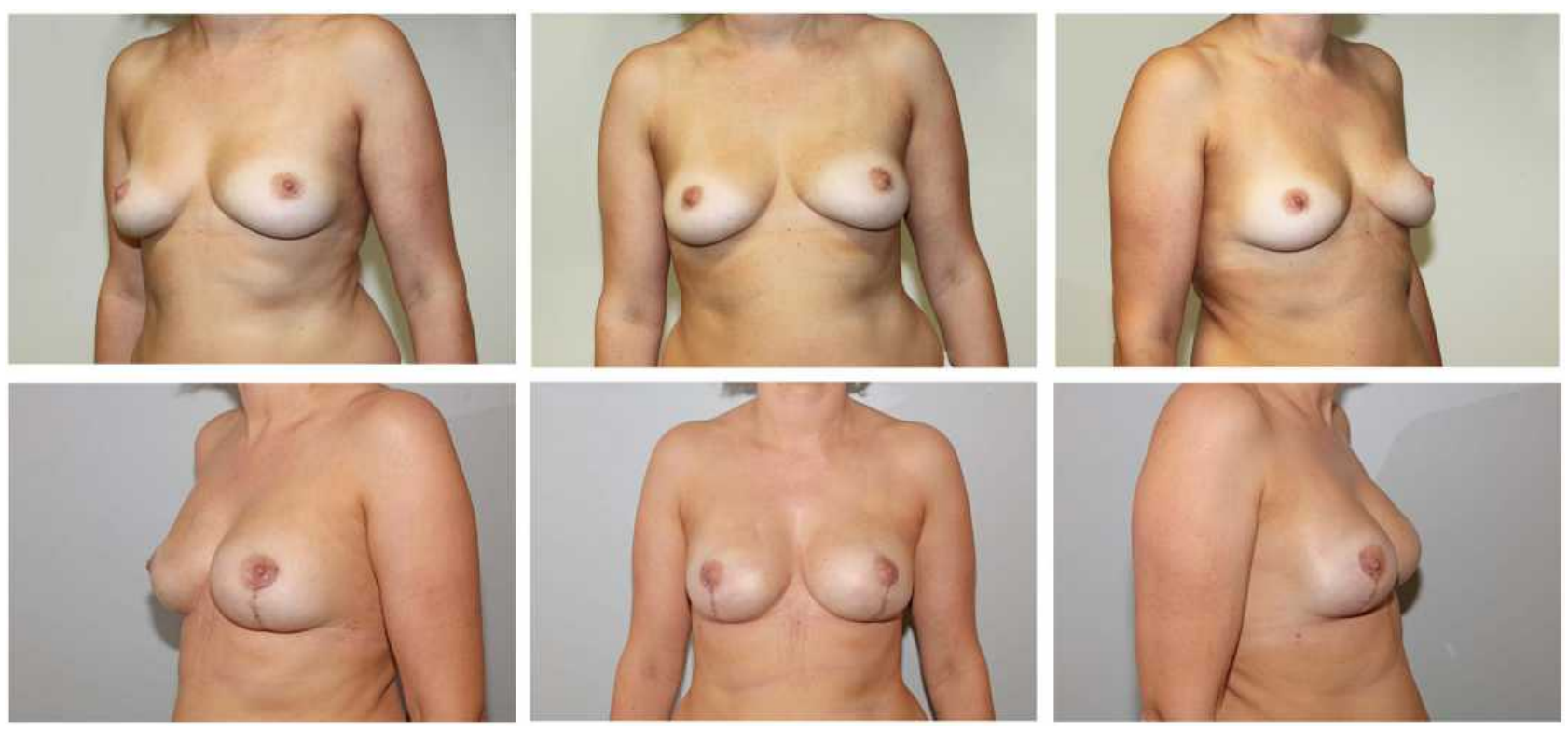

Figure I Pre- and postoperative photographs of a patient who underwent risk reducing NSM and simultaneous pre-pectoral implant-based breast reconstruction. 
the additional information assessed included: satisfaction with information and the surgeon, medical team, and office staff. Responses to each item in the scales were analyzed using the Q Score software program (Q Portfolio, New York, NY, USA), which converts raw data into summary scores ranging from 0-100. For all BREAST-Q scales, a higher score indicated a better quality of life with greater satisfaction. All domain scores were analyzed pre- and postoperatively.

\section{Statistical Analyses}

In patients without cancer gene mutations but with a suspicious family history or lifetime cancer risk $>30 \%$, the lifetime risk was calculated using the standardized prediction model, Cyrillic 2.1.3.

Continuous variables were reported as mean \pm SD and categorical variables as number (percentage). Evaluation of SF-36 and BREAST-Q forms was performed using Shapiro-Wilk, Mann-Whitney U, and $t$-tests. All statistical analyses were conducted using SPSS Statistics, version 25.0 (IBM Corp., Armonk, NY, USA). P values $<0.05$ were considered statistically significant.

\section{Results}

\section{Demographic and Clinical Characteristics} Between May 2012 and December 2017, 35 patients underwent risk-reducing mastectomy with simultaneous implant-based BR. The average age was 40.11 (range: 28-58) years. The average body mass index (BMI) was 27 (range: $18-52$ ) $\mathrm{kg} / \mathrm{m}^{2}$, and 11 patients had a history of constant nicotine abuse. $B R C A 1, B R C A 2$, and partner and localizer of $B R C A 2$ (PALB2) gene mutations were found in 19, 13, and one patient, respectively. Concurrently, two patients had no gene mutations but had an increased risk of breast and ovarian cancer and an estimated lifetime risk of $30 \%$. The mastectomy procedure preferred by patients was considered in the therapeutic decision. Twenty-six patients were treated by NSM and nine by SSM.
For BR, wise pattern mastopexy was performed in all patients. The mean weight of the gland averaged $340 \pm 180$ g (range: $80-820 \mathrm{~g}$ ), whereas the mean implant size averaged $320 \pm 65 \mathrm{cc}$ (range: $85-490 \mathrm{cc}$ ). Intraoperatively, clinical examination of the mastectomy flaps was performed to evaluate viability. All showed an appropriate capillary refill time.

Twenty-two patients participated in the follow-up evaluations and were included in the final analyses. The postoperative questionnaires were answered during the follow-up examination. The patients were divided into the NSM $(n=17)$ and SSM $(\mathrm{n}=5)$ groups. The groups were matched, and no significant differences in the race $(\mathrm{p}=1.00)$, BMI $(\mathrm{p}=0.612)$, and age $(\mathrm{p}=0.543)$ were observed. However, for the intergroup comparison, the sample size (especially that of the SSM group) was too small to evaluate establish the superiority of one group; This comparison was therefore disregarded.

At follow-up, 21 patients showed no impairment of shoulder range of motion. Two patients complained about an uncomfortable restricted feeling during shoulder movements in daily life. However, a restriction in range of motion could not be detected.

Three patients had an early postoperative infection, which healed fully after antibiotic administration. One patient developed a hematoma. Another patient developed a seroma, requiring a single aspiration. No nipple-areolar complex (NAC) necrosis was found postoperatively or at the follow-up.

At the follow-up consultation, four patients showed a capsular contraction grade of 3-4 (Baker). Postoperative infection and impaired wound healing were observed in one patient each. Bottoming-out of the implant was seen in one patient as a late complication. Inspection of the breasts showed hypertrophic scars in three patients. Other wounds healed without any signs of irritation. There was no significant difference between breasts in terms of typical measurements, showing that a symmetrical BR was achieved (Table 1).

Table I Postoperative Symmetry Between the Right and Left Breasts

\begin{tabular}{|l|l|l|}
\hline Domain & Average Difference Between the Right and Left Breasts & Range \\
\hline Jugular-mammillary distance & $1.00 \mathrm{~cm} \pm 0.69$ & $0-2.0 \mathrm{~cm}$ \\
\hline Mammillary-sternal distance & $0.69 \mathrm{~cm} \pm 0.69$ & $0-2.0 \mathrm{~cm}$ \\
\hline Diameters of the nipple-areolar complex & $0.47 \mathrm{~cm} \pm 0.46$ & $0-1.6 \mathrm{~cm}$ \\
\hline Nipple-to-inframammary crease & $0.83 \mathrm{~cm} \pm 1.05$ & $0-3.8 \mathrm{~cm}$ \\
\hline
\end{tabular}




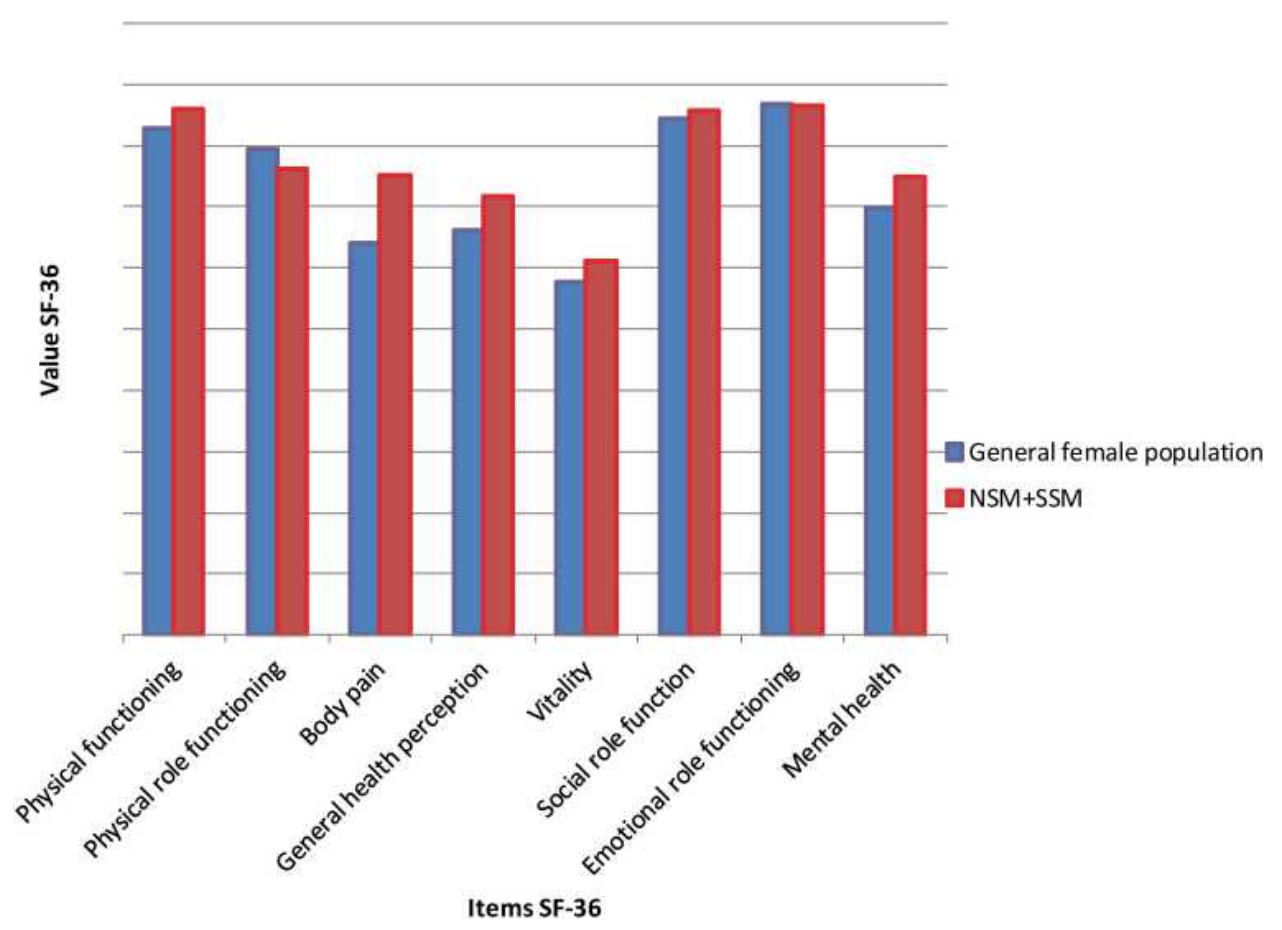

Figure 2 Results of the SF-36 quality of life questionnaire following mastectomy in the immediate implant-based reconstruction group and the general female population. Red column represents our data collected during this study, blue column represents the data from Bullinger and Kirchberger. ${ }^{27}$

\section{SF-36 Results}

In the follow-up period, the mean SF-36 scores were: physical functioning $85.90 \pm 15.47$; physical role functioning $76.13 \pm 35.75$; bodily pain $75.09 \pm 22.73$; general health perception $71.63 \pm 18.64$; vitality $61.13 \pm 17.85$; social role function $85.79 \pm 22.91$; emotional role functioning $86.36 \pm 31.97$; and mental health $74.90 \pm 8.27$. Figure 2 shows the SF-36 findings and illustrates the course in contrast to standardized reference values of the general female population. ${ }^{27}$

Compared to reference values, a significantly higher score was recorded for the body pain domain $(p=0.043)$ in our population. For other domains, no significant difference was identified: physical functioning $(\mathrm{p}=0.508)$, physical role functioning $(\mathrm{p}=0.678)$, general health perception $(\mathrm{p}=0.160)$, vitality $(\mathrm{p}=0.361)$, social role function $(p=0.731)$, emotional role functioning $(p=0.952)$, and mental health $(\mathrm{p}=0.175)$.

\section{BREAST-Q Results}

Comparing pre- and postoperative results, we observed a significant decrease in physical well-being of the chest $(p=0.0179)$ and a slight improvement in satisfaction with the breast $(\mathrm{p}=0.3266)$ (Table 2).

All patients were satisfied with the results of surgery, reconstruction, and perioperative care by the surgeon.
Postoperatively, 12 patients had a unilateral breast grade I sensitivity deficit, whereas six patients had a bilateral breast grade I sensitivity deficit. The main lack of sensation was around the NAC in all patients, correlating with the border of flaps very distal to the mastectomy site.

\section{Discussion}

Our study showed a significantly higher score in the SF-36 bodily pain domain (SF-36) than the general female population. All other domains showed no significant difference. Examination of the breast score revealed a significant decrease in the physical well-being as well as, though statistically not significant, a clear improvement in breast satisfaction. Although we expected a lack of touch sensitivity during follow-up, impaired wound healing and pathological capsular contractions were unexpected.

Although BRRM is radical, it is the most effective method for reducing the risk of breast cancer due to germline mutation or hereditary causes in healthy women. ${ }^{11,13,32,33}$ It is associated with a breast cancer risk reduction of up to $93 \%{ }^{34}$ and the mortality rate is reduced postoperatively. ${ }^{35}$ Although there is no fixed associated value for threshold risk, in women with highly penetrant genes or strong family history, careful analysis of the 
Table 2 Satisfaction Based on the Pre- and Postoperative Breast-Q Score, Surgery Outcome, and Hospital Staff Behavior in Women $(n=22)$ Who Underwent Nipple-Sparing Mastectomy and Skin-Sparing Mastectomy

\begin{tabular}{|c|c|c|c|}
\hline Domain & Preoperative $(n=22)($ Mean \pm SD $)$ & Postoperative $(n=22)($ Mean $\pm S D)$ & p-value \\
\hline Satisfaction with the breast & $64.86 \pm 22.36$ & $70.33 \pm 11.98$ & 0.3266 \\
\hline Psychosocial well-being & $77.86 \pm|7.3|$ & $78.73 \pm 19.28$ & 0.9292 \\
\hline Physical well-being of the chest & $79.32 \pm 14.87$ & $68.27 \pm 14.86$ & 0.0179 \\
\hline Sexual well-being & $59.10 \pm 11.30$ & $58.17 \pm 20.10$ & 0.7423 \\
\hline Satisfaction with the results & & $75.50 \pm 19.39$ & \\
\hline Satisfaction with information & & $73.45 \pm 23.49$ & \\
\hline Satisfaction with the surgeon & & $83.23 \pm 18.32$ & \\
\hline Satisfaction with the medical staff & & $86.36 \pm 17.23$ & \\
\hline Satisfaction with the office staff & & $90.45 \pm 16.83$ & \\
\hline
\end{tabular}

Abbreviation: SD, standard deviation.

benefit-risk ratio must be performed. ${ }^{36,37}$ Furthermore, the possibility of a conservative approach should be considered. However, as represented in our population, patients with germline mutations or those at an increased risk due to their family history often opted for a risk-reducing mastectomy with immediate reconstruction. ${ }^{38}$

NSM and SSM are appropriate for mutation carriers and are oncologically safe. ${ }^{11-13}$ Far beyond its importance as an organ, the breast is a visible symbol of femininity, attractiveness, and sexuality. ${ }^{39}$ Risk-reducing mastectomy has a great impact on appearance, as well as on the patients' physical, social, and psychological functioning. ${ }^{16,40-42}$ Therefore, simultaneous reconstruction of the breast is important to preserve esthetics and patient self-esteem. Retention of the NAC as performed in NSM further provides the patient with a sense of wholeness and greatly impacts the decision-making process of patients considering BRRM. ${ }^{43}$ In 2017, Bailey et al showed that patients who underwent NSM had a better HRQoL than patients who underwent SSM. ${ }^{44}$ Furthermore, NAC preservation has been shown to improve body image due to a closer similarity with the patient's original breast and a more positive psychological aspect. ${ }^{39,45-47}$ Another advantage is that in the case of a larger or ptotic breast, reshaping of the breast envelope can be performed, thereby improving form and appearance of the breast, ${ }^{48}$ and a previously failed symmetry or adjustment of ptotic or larger breasts can be corrected. Even though most women have breast asymmetry, symmetrical appearance is one of the most important factors influencing patient satisfaction. ${ }^{49}$ Therefore, NSM was the preferred surgical procedure in the enrolled patients.

For women with a future risk of breast cancer and considering BRRM, the focus of the consultation lies not only on providing clinical information on survival and recurrence rates, but also on HRQoL and body image, as well as psychosocial aspects. ${ }^{46,50}$ Therefore, preoperative information regarding the expected HRQoL influences the decision-making process of women considering prophylactic bilateral mastectomy. ${ }^{51}$

The SF-36 results of our sample differed only slightly from that of the general female population. This indicates that risk-reducing mastectomy and simultaneous BR have only a minor influence on the physical and psychological values 2 years postoperatively. These results are largely consistent with the current literature. ${ }^{52,53}$ However, in our patients, a significantly higher score in the pain domain was recorded. This seems contradictory; however, high scores in the domain "pain" represents a characteristic painlessness. Often, respondents include all kinds of pain (headache, back pain, etc.) when answering the pain questions, and answers are not limited to the patients in the study related the question not to only surgery-associated chest pain. If we considered the above, it meant that we recorded less pain in our sample compared to the general population, which included those with both acute and chronic illness.

However, some changes in the HRQoL due to BRRM are typically related to self-image and body image and are not well represented in SF-36 scales. Moreover, because of these potential limitations, we used the BREAST-Q to capture 
items representing female self-esteem and body image. Though not statistically significant, a clear improvement in satisfaction within the breast domain was observed. The improvement in this domain was most likely due to the appealing postoperative esthetic appearance of the breasts, which compensates for the psychological trauma of mastectomy. ${ }^{54}$ Ueda et al suggested that a persistent high score in psychological well-being may be an indirect result of the esthetic outcome. ${ }^{55}$ Furthermore, sexual well-being scores remained consistently low. The low level in this domain is most likely due to the embarrassment of being confronted with such intimate details. ${ }^{10,16,56}$ We recorded a significant decrease in physical well-being. Although this result was disappointing, it is consistent with the current literature. ${ }^{57,58}$

Despite appealing esthetic results, animation deformity, muscle spasm, and postoperative pain remain potential consequences of subpectoral placement that can significantly affect the quality of life. ${ }^{59,60}$ Furthermore, the implant in the subpectoral plane may only be partially covered. To complete the pocket and fully protect the implant, an acellular dermal matrix is often used, thereby a naturally appearing breast without compromising the mastectomy flaps can be created. ${ }^{61}$ However, Thangarajah et al showed a comparison of sub- and pre-pectoral implant-based reconstruction of the breast following NSM and SSM where the physical wellbeing and the other domains of the HRQoL were similar in both groups. ${ }^{48}$ Furthermore, the sub-pectoral group had a significantly higher rate of major complications. ${ }^{62}$ Additionally, due to the extensive manipulation of the pectoralis muscle, stronger pain and longer recovery time were observed in this population. ${ }^{63-65}$ In the pre-pectoral plane, an acellular dermal matrix can be used to build a pocket for the implant, or even be completely wrapped around the implant and anchor it to the chest wall. ${ }^{61,66}$ Hereby, a stable position of the fully covered implant is achieved, and additionally pressure is taken off of the skin flaps. ${ }^{67,68}$

In case of persistent breast discomfort, revision and reconstruction with an autologous tissue transfer are helpful alternatives. The free deep inferior epigastric artery perforator flap technique is a well-established procedure resulting in a more natural appearance and movement of the breast, which meets the patient's requirement for a natural physiological feel. HRQoL analyses have revealed significantly higher satisfaction with breasts and physical well-being using this technique. ${ }^{22,69-71}$ However, "feeling of well-being" decreases drastically after autologous BR due to abdominal donor-site morbidity. ${ }^{69}$ Reconstruction is a complex procedure requiring excellent microsurgical expertise, and it is accompanied by a longer intraoperative time of up to 8-10 hours in bilateral reconstruction, a longer postoperative recovery period, and possible donor-site complications. ${ }^{71}$

As earlier presented by Sullivan et al, our study found no association between BMI and complications after BRRM. ${ }^{72}$ As repeatedly described in the literature, we found that the prevalence of early complications such as impaired wound healing was higher in the smoking sub-population than in nonsmoking women. ${ }^{4,73}$ Although the difference was not statistically significant, it did influence HRQoL outcome.

There were some limitations in our study design. Although we were able to demonstrate the statistical significance in our analyses, our sample size was rather small. Furthermore, the rating of the medical team may contain a bias due to the subjective in rating. Nevertheless, we were able to match the NSM and SSM groups by race, sex, BMI, and age. The sample size, especially in the SSM group, was too small to establish the superiority of one group over the other in an intergroup comparison.

\section{Conclusion}

Patients undergoing bilateral mastectomy with simultaneous BR using pre-pectoral implants possess an HRQoL equal to that of healthy women. Apart from the reduced physical wellbeing regarding the chest, HRQoL remained constant in the pre- and postoperative periods. Furthermore, an improvement in breast satisfaction was observed in our study. We found no significant psychological differences between the pre- and postoperative situations. However, a bilateral mastectomy is a stressful experience for a woman which can have immense effects on psychological, physical, and social well-being. Therefore, we recommend that in daily clinical practice, immediate reconstruction of the breasts should be performed as it preserves the esthetic appearance of the breasts, thereby improving patient self-esteem.

\section{Abbreviations}

BRCA, Breast cancer gene; BRRM, Bilateral riskreducing mastectomy; BMI, Body mass index; HRQoL, Health-related quality of life play; JMD, Jugularmammillary distance; NAC, Nipple-areolar complex; PALB2, Partner and Localizer of BRCA2.

\section{Data Sharing Statement}

Raw and analyzed data are available from the corresponding author on reasonable request. 


\section{Ethical Approval}

All procedures were in accordance with the ethical standards of the local ethics committee of the University of Leipzig (021/17-ek) and with the 1964 Helsinki Declaration and its later amendments or comparable ethical standards. The study has been registered at the German clinical study register (DRKS00024043).

\section{Informed Consent}

The participants provided written informed consent for participation in this study, and for the publication of all data and accompanying images.

\section{Funding}

This study was supported by the German Research Foundation and Leipzig University within the Open Access Publishing program.

\section{Disclosure}

Dr Susanne Briest reports honoraria for presentations or participation and aboard or support for travelling to conferences from Pfizer, Genomic Health, Eisai, Lilly, Daiichi Sankyo, Amgen, Pierre Fabre, Roche, AstraZeneca, Janssen, Novartis, and Teva, outside the submitted work. The other authors declare that they have no conflicts of interest in this work.

\section{References}

1. Lostumbo L, Carbine NE, Wallace J. Prophylactic mastectomy for the prevention of breast cancer. Cochrane Database Syst Rev. 2010; CD002748. doi:10.1002/14651858.CD002748.pub3

2. Beral V, Million Women Study Collaborators. Breast cancer and hormone-replacement therapy in the Million Women Study. Lancet. 2003;362:419-427. doi:10.1016/s0140-6736(03)14065-2

3. Morch LS, Skovlund CW, Hannaford PC, Iversen L, Fielding S, Lidegaard O. Contemporary hormonal contraception and the risk of breast cancer. $N$ Engl J Med. 2017;377:2228-2239. doi:10.1056/ NEJMoa 1700732

4. Keeney MG, Couch FJ, Visscher DW, Lindor NM. Non-BRCA familial breast cancer: review of reported pathology and molecular findings. Pathology. 2017;49:363-370. doi:10.1016/j.pathol.2017.03.002

5. Balmana J, Diez O, Rubio IT, Cardoso F, ESMO Guidelines Working Group. BRCA in breast cancer: ESMO clinical practice guidelines. Ann Oncol. 2011;22:vi31-vi34. doi:10.1093/annonc/mdr373

6. Hartmann LC, Schaid DJ, Woods JE, et al. Efficacy of bilateral prophylactic mastectomy in women with a family history of breast cancer. $N$ Engl $J$ Med. 1999;340:77-84. doi:10.1056/ NEJM199901143400201

7. Domchek SM, Friebel TM, Singer CF, et al. Association of risk-reducing surgery in BRCA1 or BRCA2 mutation carriers with cancer risk and mortality. JAMA. 2010;304:967-975. doi:10.1001/ jama.2010.1237
8. Rebbeck TR, Friebel T, Lynch HT, et al. Bilateral prophylactic mastectomy reduces breast cancer risk in BRCA1 and BRCA2 mutation carriers: the PROSE Study Group. $J$ Clin Oncol. 2004;22:1055-1062. doi:10.1200/JCO.2004.04.188

9. Meijers-Heijboer H, van Geel B, van Putten WL, et al. Breast cancer after prophylactic bilateral mastectomy in women with a BRCA1 or BRCA2 mutation. $N$ Engl J Med. 2001;345:159-164. doi:10.1056/ NEJM200107193450301

10. Howard MA, Sisco M, Yao K, et al. Patient satisfaction with nipple-sparing mastectomy: a prospective study of patient reported outcomes using the BREAST-Q. J Surg Oncol. 2016;114(4):416-422. doi: $10.1002 /$ jso. 24364

11. Jakub JW, Peled AW, Gray RJ, et al. Oncologic safety of prophylactic nipple-sparing mastectomy in a population with BRCA mutations: a multi-institutional study. JAMA Surg. 2018;153:123-129. doi:10.1001/jamasurg.2017.3422

12. Maxwell GP, Storm-Dickerson T, Whitworth P, Rubano C, Gabriel A. Advances in nipple-sparing mastectomy: oncological safety and incision selection. Aesthet Surg J. 2011;31:310-319. doi:10.1177/ 1090820X11398111

13. Reynolds C, Davidson JA, Lindor NM, et al. Prophylactic and therapeutic mastectomy in BRCA mutation carriers: can the nipple be preserved? Ann Surg Oncol. 2011;18(11):3102-3109. doi:10.1245/ s10434-011-1908-8

14. González EG, Rancatti AO. Skin-sparing mastectomy. Gland Surg. 2015;4:541-553. doi:10.3978/j.issn.2227-684X.2015.04.21

15. Thorat MA, Balasubramanian R. Breast cancer prevention in high-risk women. Best Pract Res Clin Obstet Gynaecol. 2020;65:18-31. doi:10.1016/j.bpobgyn.2019.11.006

16. Wei $\mathrm{CH}$, Scott AM, Price AN, et al. Psychosocial and sexual well-being following nipple-sparing mastectomy and reconstruction. Breast J. 2016;22:10-17. doi:10.1111/tbj.12542

17. Lins L, Carvalho FM. SF-36 total score as a single measure of health-related quality of life: scoping review. SAGE Open Med. 2016;4:2050312116671725. doi:10.1177/2050312116671725

18. Morfeld M, Kirchberger I, Bullinger M. Short-Form-36 Health Survey. Göttingen, Germany: Hogrefe Verlag GmbH \& Co. KG; 2011.

19. Turner-Bowker DM, Saris-Baglama RN, DeRosa MA, Giovannetti ER, Jensen RE, Wu AW. A computerized adaptive version of the SF-36 is feasible for clinic and internet administration in adults with HIV. AIDS Care. 2012;24:886-896. doi:10.1080/ 09540121.2012.656573

20. Treanor C, Donnelly M. A methodological review of the short form health survey 36 (SF-36) and its derivatives among breast cancer survivors. Qual Life Res. 2015;24(2):339-362. doi:10.1007/s11136014-0785-6

21. Pusic AL, Chen CM, Cano S, et al. Measuring quality of life in cosmetic and reconstructive breast surgery: a systematic review of patient-reported outcomes instruments. Plast Reconstr Surg. 2007;120(4):823-829. doi:10.1097/01.prs.0000278162.82906.81

22. Pusic AL, Matros E, Fine N, et al. Patient-reported outcomes 1 year after immediate breast reconstruction: results of the Mastectomy Reconstruction Outcomes Consortium study. J Clin Oncol. 2017;35 (22):2499-2506. doi:10.1200/JCO.2016.69.9561

23. Cohen WA, Mundy LR, Ballard TN, et al. The BREAST-Q in surgical research: a review of the literature 2009-2015. J Plast Reconstr Aesthet Surg. 2016;69:149-162. doi:10.1016/j. bjps.2015.11.013

24. Cano SJ, Klassen AF, Scott AM, Cordiero PG, Pusic AL. The BREAST-Q: further validation in independent clinical samples. Plast Reconstr Surg. 2012;129:293-302. doi:10.1097/ PRS.0b013e31823aec6b

25. Colizzi L, Lazzeri D, Agostini T, et al. Skin-reducing mastectomy: new refinements. J Plast Surg Hand Surg. 2010;44:296-301. doi:10.3109/2000656X.2010.517681 
26. Downie WW, Leatham PA, Rhind VM, Wright V, Branco JA, Anderson JA. Studies with pain rating scales. Ann Rheum Dis. 1978;37:378-381. doi:10.1136/ard.37.4.378

27. Bullinger M, Kirchberger I. Short-Form-36 Health Survey. Göttingen, Germany: Hogrefe Verlag GmbH \& Co. KG; 1998.

28. Hays RD, Sherbourne CD, Mazel RM. The RAND 36-item health survey 1.0. Health Econ. 1993;2:217-227. doi:10.1002/hec.4730020305

29. Dean NR, Crittenden T. A five year experience of measuring clinical effectiveness in a breast reconstruction service using the BREAST-Q patient reported outcomes measure: a cohort study. $J$ Plast Reconstr Aesthet Surg. 2016;69(11):1469-1477. doi:10.1016/j.bjps.2016.08.015

30. Howes BH, Watson DI, Xu C, Fosh B, Canepa M, Dean NR. Quality of life following total mastectomy with and without reconstruction versus breast-conserving surgery for breast cancer: a case-controlled cohort study. J Plast Reconstr Aesthet Surg. 2016;69:1184-1191. doi:10.1016/j.bjps.2016.06.004

31. Zhong T, Hu J, Bagher S, et al. A comparison of psychological response, body image, sexuality, and quality of life between immediate and delayed autologous tissue breast reconstruction: a prospective long-term outcome study. Plast Reconstr Surg. 2016;138:772-780. doi:10.1097/PRS.0000000000002536

32. Mau C, Untch M. Prophylactic surgery: for whom, when and how? Breast Care. 2017;12:379-384. doi:10.1159/000485830

33. Tung NM, Boughey JC, Pierce LJ, et al. Management of hereditary breast cancer: American Society of Clinical Oncology, American Society for Radiation Oncology, and Society of Surgical Oncology Guideline. J Clin Oncol. 2020:JCO2000299. doi:10.1200/ JCO.20.00299

34. De Felice F, Marchetti C, Musella A, et al. Bilateral risk-reduction mastectomy in BRCA1 and BRCA2 mutation carriers: a meta-analysis. Ann Surg Oncol. 2015;22:2876-2880. doi:10.1245/ s10434-015-4532-1

35. Domchek SM. Risk-reducing mastectomy in BRCA1 and BRCA2 mutation carriers: a complex discussion. JAMA. 2019;321:27. doi:10.1001/jama.2018.18942

36. Hunt KK, Euhus DM, Boughey JC, et al. Society of surgical oncology breast disease working group statement on prophylactic (risk-reducing) mastectomy. Ann Surg Oncol. 2017;24:375-397. doi:10.1245/s10434-016-5688-z

37. Carbine NE, Lostumbo L, Wallace J, Ko H. Risk-reducing mastectomy for the prevention of primary breast cancer. Cochrane Database Syst Rev. 2018;4:CD002748. doi:10.1002/14651858.CD002748.pub4

38. Hermel DJ, Wood ME, Chun J, et al. Multi-institutional evaluation of women at high risk of developing breast cancer. Clin Breast Cancer. 2017;17:427-432. doi:10.1016/j.clbc.2017.04.005

39. Didier F, Arnaboldi P, Gandini S, et al. Why do women accept to undergo a nipple sparing mastectomy or to reconstruct the nipple areola complex when nipple sparing mastectomy is not possible? Breast Cancer Res Treat. 2012;132:1177-1184.

40. Matthews H, Carroll N, Renshaw D, et al. Predictors of satisfaction and quality of life following post-mastectomy breast reconstruction. Psychooncology. 2017;26:1860-1865. doi:10.1002/pon.4397

41. Eltahir Y, Werners LL, Dreise MM, et al. Quality-of-life outcomes between mastectomy alone and breast reconstruction: comparison of patient-reported BREAST-Q and other health-related quality-of-life measures. Plast Reconstr Surg. 2013;132:201e-209e. doi:10.1097/ PRS.0b013e31829586a7

42. Sugrue R, MacGregor G, Sugrue M, Curran S, Murphy L. An evaluation of patient reported outcomes following breast reconstruction utilizing breast Q. Breast. 2013;22:158-161. doi:10.1016/j. breast.2012.12.001

43. Wellisch DK, Schain WS, Noone RB, Little JW 3rd. The psychological contribution of nipple addition in breast reconstruction. Plast Reconstr Surg. 1987;80:699-704. doi:10.1097/00006534-19871100000007
44. Bailey CR, Ogbuagu O, Baltodano PA, et al. Quality-of-life outcomes improve with nipple-sparing mastectomy and breast reconstruction. Plast Reconstr Surg. 2017;140:219-226. doi:10.1097/PRS.0000000000003505

45. Metcalfe KA, Cil TD, Semple JL, et al. Long-term psychosocial functioning in women with bilateral prophylactic mastectomy: does preservation of the nipple-areolar complex make a difference? Ann Surg Oncol. 2015;22:3324-3330. doi:10.1245/s10434-015-4761-3

46. Hamelinck VC, Bastiaannet E, Pieterse AH, et al. Patients' preferences for surgical and adjuvant systemic treatment in early breast cancer: a systematic review. Cancer Treat Rev. 2014;40:1005-1018. doi:10.1016/j.ctrv.2014.06.007

47. Didier F, Radice D, Gandini S, et al. Does nipple preservation in mastectomy improve satisfaction with cosmetic results, psychological adjustment, body image and sexuality? Breast Cancer Res Treat. 2009;118:623-633.

48. Al-Mufarrej FM, Woods JE, Jacobson SR. Simultaneous mastopexy in patients undergoing prophylactic nipple-sparing mastectomies and immediate reconstruction. $J$ Plast Reconstr Aesthet Surg. 2013;66:747-755. doi:10.1016/j.bjps.2013.02.007

49. Barone M, Cogliandro A, Signoretti M, Persichetti P. Analysis of symmetry stability following implant-based breast reconstruction and contralateral management in 582 patients with long-term outcomes. Aesthet Plast Surg. 2018;42:936-940. doi:10.1007/s00266-018-1082-5

50. Potter S, Brigic A, Whiting PF, et al. Reporting clinical outcomes of breast reconstruction: a systematic review. $J$ Natl Cancer Inst. 2011;103:31-46. doi:10.1093/jnci/djq438

51. Razdan SN, Patel V, Jewell S, McCarthy CM. Quality of life among patients after bilateral prophylactic mastectomy: a systematic review of patient-reported outcomes. Qual Life Res. 2016;25:1409-1421. doi:10.1007/s11136-015-1181-6

52. Cocquyt VF, Blondeel PN, Depypere HT, et al. Better cosmetic results and comparable quality of life after skin-sparing mastectomy and immediate autologous breast reconstruction compared to breast conservative treatment. $\mathrm{Br} \quad J$ Plast Surg. 2003;56:462-470. doi:10.1016/s0007-1226(03)00198-x

53. Alderman AK, Wilkins EG, Lowery JC, Kim M, Davis JA. Determinants of patient satisfaction in postmastectomy breast reconstruction. Plast Reconstr Surg. 2000;106:769-776. doi:10.1097/00006534-200009040-00003

54. Murthy V, Chamberlain RS. Defining a place for nipple sparing mastectomy in modern breast care: an evidence based review. Breast J. 2013;19:571-581. doi:10.1111/j.1524-4741.2011.01220.x

55. Ueda S, Tamaki Y, Yano K, et al. Cosmetic outcome and patient satisfaction after skin-sparing mastectomy for breast cancer with immediate reconstruction of the breast. Surgery. 2008;143:414-425. doi:10.1016/j.surg.2007.10.006

56. Ghilli M, Mariniello MD, Camilleri V, et al. PROMs in postmastectomy care: patient self-reports (BREAST-Q ${ }^{\mathrm{TM}}$ ) as a powerful instrument to personalize medical services. Eur J Surg Oncol. 2020;46:1034-1040. doi:10.1016/j.ejso.2019.11.504

57. McCarthy CM, Hamill JB, Kim HM, Qi J, Wilkins E, Pusic AL. Impact of bilateral prophylactic mastectomy and immediate reconstruction on health-related quality of life in women at high risk for breast carcinoma: results of the Mastectomy Reconstruction Outcomes Consortium Study. Ann Surg Oncol. 2017;24:2502-2508. doi:10.1245/s10434-017-5915-2

58. Peled AW, Duralde E, Foster RD, et al. Patient-reported outcomes and satisfaction after total skin-sparing mastectomy and immediate expander-implant reconstruction. Ann Plast Surg. 2014;72:S48-S52. doi: 10.1097/SAP.0000000000000020

59. Fracol M, Feld LN, Chiu W-K, Kim JYS. An overview of animation deformity in prosthetic breast reconstruction. Gland Surg. 2018;8:95-101.

60. Baker BG, Irri R, MacCallum V, Chattopadhyay R, Murphy J, Harvey JR. A prospective comparison of short-term outcomes of subpectoral and prepectoral strattice-based immediate breast reconstruction. Plast Reconstr Surg. 2018;141:1077-1084. doi:10.1097/prs.000000 0000004270 
61. Maruccia M, Mazzocchi M, Dessy LA, Onesti MG. One-stage breast reconstruction techniques in elderly patients to preserve quality of life. Eur Rev Med Pharmacol Sci. 2016;20:5058-5066.

62. Thangarajah F, Treeter T, Krug B, et al. Comparison of subpectoral versus prepectoral immediate implant reconstruction after skin- and nipple-sparing mastectomy in breast cancer patients: a retrospective hospital-based cohort study. Breast Care. 2019;14:382-387. doi:10.1159/000496696

63. Becker H, Lind JG 2nd, Hopkins EG. Immediate implant-based prepectoral breast reconstruction using a vertical incision. Plast Reconstr Surg Glob Open. 2015;3:e412. doi:10.1097/ GOX.0000000000000384

64. Sigalove S, Maxwell GP, Sigalove NM, et al. Prepectoral implant-based breast reconstruction: rationale, indications, and preliminary results. Plast Reconstr Surg. 2017;139:287-294. doi:10.1097/PRS.0000000000002950

65. Onesti MG, Maruccia M, Di Taranto G, et al. Clinical, histological, and ultrasound follow-up of breast reconstruction with one-stage muscle-sparing "wrap" technique: a single-center experience. J Plast Reconstr Aesthet Surg. 2017;70:1527-1536. doi:10.1016/j. bjps.2017.06.023

66. Maruccia M, Di Taranto G, Onesti MG. One-stage muscle-sparing breast reconstruction in elderly patients: a new tool for retaining excellent quality of life. Breast J. 2018;24:180-183. doi:10.1111/ tbj. 12860

67. Macadam S, Lennox PA. Acellular dermal matrices: use in reconstructive and aesthetic breast surgery. Can J Plast Surg. 2012;20:75-89. doi:10.1177/229255031202000201
68. Maruccia M, Elia R, Gurrado A, et al. Skin-reducing mastectomy and pre-pectoral breast reconstruction in large ptotic breasts. Aesth Plast Surg. 2020;44:664-672. doi:10.1007/s00266-020-01616-2

69. Santosa KB, Qi J, Kim HM, Hamill JB, Wilkins EG, Pusic AL. Long-term patient-reported outcomes in postmastectomy breast reconstruction. JAMA Surg. 2018;153:891-899. doi:10.1001/ jamasurg.2018.1677

70. Yueh JH, Slavin SA, Adesiyun T, et al. Patient satisfaction in postmastectomy breast reconstruction: a comparative evaluation of DIEP, TRAM, latissimus flap, and implant techniques. Plast Reconstr Surg. 2010;125:1585-1595. doi:10.1097/PRS.0b013e3181cb6351

71. Pirro O, Mestak O, Vindigni V, et al. Comparison of patient-reported outcomes after implant versus autologous tissue breast reconstruction using the BREAST-Q. Plast Reconstr Surg Glob Open. 2017;5: e1217. doi:10.1097/GOX.0000000000001217

72. Sullivan SR, Fletcher DR, Isom CD, Isik FF. True incidence of all complications following immediate and delayed breast reconstruction. Plast Reconstr Surg. 2008;122:19-28. doi:10.1097/ PRS.0b013e3181774267

73. Woerdeman LA, Hage JJ, Hofland MM, Rutgers EJT. A prospective assessment of surgical risk factors in 400 cases of skin-sparing mastectomy and immediate breast reconstruction with implants to establish selection criteria. Plast Reconstr Surg. 2007;119:455-463. doi:10.1097/01.prs.0000246379.99318.74
Patient Preference and Adherence

\section{Publish your work in this journal}

Patient Preference and Adherence is an international, peer-reviewed, open access journal that focusing on the growing importance of patient preference and adherence throughout the therapeutic continuum. Patient satisfaction, acceptability, quality of life, compliance, persistence and their role in developing new therapeutic modalities and compounds to optimize clinical outcomes for existing disease states are major areas of interest for the journal. This journal has been accepted for indexing on PubMed Central. The manuscript management system is completely online and includes a very quick and fair peer-review system, which is all easy to use. Visit http:// www.dovepress.com/testimonials.php to read real quotes from published authors. 